\title{
DALADALA BUSES DEREGULATED - ANALYSING URBANISATION'S SITUATIONS OF OPPORTUNITY VIA TANZANIAN EXAMPLE
}

\author{
C. WEINGAERTNER ${ }^{1}$, Ö. SVANE ${ }^{1} \&$ B. BRIKELL ${ }^{2}$ \\ ${ }^{1}$ Department of Urban Planning and Environment, Royal Institute of Technology, Sweden. \\ ${ }^{2}$ Jönköping International Business School, Jönköping University, Sweden.
}

\begin{abstract}
In the development and growth of cities, certain stages or segments in time are considered more important than the others. Analysts have identified these points in time as 'formative moments', 'policy windows' or 'situations of opportunity', and argue that they present policy makers and stakeholders with a unique opportunity to implement change. Thus, in an ongoing project, Managing the Metabolism of Urbanisation (MAMMUT), we need methods for identifying and analysing this kind of situations in historical processes as well as in backcasting from future scenarios. When did these situations open up and what did they consist of? Was the process intentional, accidental or even the effect of an evolutionary process? Furthermore, which was, in terms of the MAMMUT project, the 'field of options' available to the stakeholders? (in historical situations, we can identify counterfactual alternatives though they were not elaborate or even considered at that time). From political scientist Rothstein we get the means for identifying formative moments in institutional processes of decision-making. Elinor Ostrom supplies theory that should facilitate the analysis of situations of opportunity. In order to test the feasibility of these methods in the project, we related them to findings from an empirical pilot study on the city of Dar es Salaam, Tanzania. In the pilot study, the situation of opportunity is the deregulation and privatisation of the Daladala local bus transport system from the 1970s. The pilot study indicates that this turnover indeed was a formative moment or a situation of opportunity, albeit a missed one. Furthermore, these methods could also be used for analysis, at least of the institutional aspect of the situation. The social and urban structural aspects as well as the assessment of the outcome in terms of environmental impacts call for a wider set of methodologies.
\end{abstract}

Keywords: Dar es Salaam, field of options, formative moment, methods development, public transport, situation of opportunity, sustainable urbanisation.

\section{INTRODUCTION AND BACKGROUND}

\subsection{MAMMUT and theories on formative moments}

This paper explores the extent to which a theory from political science could contribute to the development of 'Managing the Metabolism of Urbanisation' (MAMMUT), a cross-disciplinary research programme at the Royal Institute of Technology, Stockholm. The starting point is a pilot study of the development of the Daladala bus system, the main means of public transport of Dar es Salaam, Tanzania, from the 1970s onwards.

To the empirical material of the MAMMUT pilot study, here we apply the concept of formative moments as elaborated by political scientists Rothstein and Ostrom [1-3]. The main purpose of the paper is to see to what extent the theory of formative moments could assist in developing the MAMMUT concepts of situations of opportunity and field of options.

1.2 MAMMUT, urbanisation and situations of opportunity

As first step, MAMMUT begins with a discussion on recent research on sustainable cities [4]. The sustainable city has been a theme for debate for a long time. Is it the dense, traditional European city 
that has the qualities required to sustain human life in balance with nature, or are other urban structures more suitable [5, 6]? The debate seems to lead nowhere. Here, we propose a more dynamic approach to understanding of urban sustainability: we do not analyse the properties of the urban landscape and its steady-state interchange with its resource base, nature. Instead, we start with an ongoing process - that of urbanisation - and explore how it could contribute to another process of change - sustainable development. We see the former as possible to influence but not to halter; the latter as a set of long-term objectives guiding the direction that urbanisation will take.

The MAMMUT research programme was outlined in 2003 by the members of a cross-disciplinary group of senior researchers, wherein, a draft theory in the form of a conceptual framework was developed [4]. The main assumption of the project is: The process of urbanisation can be guided by its stakeholders so as to contribute to the realisation of the objectives of sustainable development; at least in certain situations of opportunity, and within a field of options that is specific to the situation.

The concept of situation of opportunity as used in the MAMMUT project is closely related to the concepts of policy windows and formative moments, found in political science and business economy [7, 8]. Based on the above assumption, pilot studies of the processes of urbanisation in Stockholm and Dar es Salaam over the past 50 years were undertaken and some situations of opportunity were identified [9].

\subsection{Stockholm's underground, Dar es Salaam's Daladala buses - two situations} of opportunity analysed

In the pilot studies of Stockholm and Dar es Salaam, we identified three historical situations of opportunity. In two of these, strategic decisions were taken that strongly influenced the future development of the cities. However, in the third the situation of opportunity was created by a weakness in the city regime [10], and the outcome was mostly negative. Two of the situations focus on public transport systems, and that of Dar es Salaam is the starting point for the discussion of this article (the Stockholm pilot study is presented in depth in [9]). In Section 1, some main results from the historical studies are presented. In parallel, the conceptual framework of MAMMUT is introduced.

In MAMMUT, we analyse the management of the process of urbanisation as a complex interplay between three aspects - urban structural development, changes in the institutional setup and people's ways of life. Furthermore, as a fourth aspect we indicate the outcome of the management process in terms of environmental impacts. This calls for an analysis of the urban metabolism. Thence the subtitle of the main programme: 'Managing the Metabolism of Urbanisation'.

In the Stockholm pilot study, we identified the development of the underground system as one situation of opportunity since the interwar period. In Dar es Salaam, the situation identified was the transition from government control to private enterprise of the main public transport system, the Daladala buses. In both cases, we pinpointed the core of the situation and briefly mapped the history leading up to that. In Stockholm, the strategic decisions for the future of the underground were taken in the early 1940s; in Dar es Salaam the government lost control over the bus system in the mid 1980s, during the transition from a planned to market oriented economy. In both cases, it seemed probable that historical development delimited the field of options but did not fully determine the development that followed.

As part of the historical pilot studies, we also created counterfactual scenarios that contrast with what really happened after the core decisions of the situation. For Stockholm, for example, we asked: "what urban structure might have been built, based on a system of roads, cars and buses instead of the underground; what institutional setup and what ways of life could have developed? 
Which outcome in terms of environmental impacts would have resulted?' We based the scenario on what was, at the time, available regarding technology, visions of city life and urban form, etc. rather than limiting it to alternatives considered in the real process. We also aimed at a scenario with an outcome that clearly contrasted against the factual one, as assessed in terms of environmental impacts.

Owing to the fact that we could create a counterfactual scenario that differs in all aspects, we now consider a criterion for the whole being a situation of opportunity. Thus, through each counterfactual scenario we outlined a field of options that was - at least in principle - available to the stakeholders of the situation.

As mentioned, analysis of urban metabolism and its resulting environmental impacts indicate the main outcome of the situation of opportunity. In the pilot studies, the impacts of the use of energy for transport was the main environmental indicator chosen, and the calculations based on material flow analysis and life cycle analysis methodology $[11,12]$ will be made in the full-scale project.

\subsection{MAMMUT theory for the analysis of historical situations of opportunity}

As mentioned previously, the draft conceptual framework of the MAMMUT programme identifies four main aspects of the intertwined processes of urbanisation and sustainable development, namely urban structural, institutional, social and environmental. These are discussed briefly here, but for a more in-depth analysis refer Svane and Weingaertner [9]. They are related to different disciplines, such as architecture and urban planning, political science, sociology and natural science, which are represented in the researchers' group.

Furthermore, the four aspects relate to the basic aspects of sustainability as defined in the Rio Declaration [13], but were adapted to the problem studied. The institutional aspect was added as suggested by researchers of the Wuppertal Institute [14]. Urban form, or the physical structure of the city, its buildings and infrastructure was another addition, necessitated by the focus on urbanisation. We have so far chosen not to integrate the economic aspect of sustainability, but in a full-scale project this might change.

In the pilot studies of Stockholm and Dar es Salaam, analysis of what followed after the core decisions of the situation of opportunity was based on the conceptual framework of MAMMUT. This applies to the factual outcome as well as the counterfactual scenario. Thus, the field of options is described in terms of the aforementioned four aspects.

However, the main focus of the MAMMUT project is not on the four aspects as separate entities. Instead, we assume that the understanding of the opportunities of the situation comes from studying the relations between the aspects [15]. In other words, urbanisation is characterised by the complex interplay between urban form, institutional setup, and people's ways of life. The resulting urban metabolism and its environmental impacts will also be involved in this interplay.

To exemplify, if it is true that the urban form of Stockholm's suburbs is the result of decisions taken by a strong local government, it is equally valid that the underground system, to some extent, determines the institutional setup. Furthermore, although the neighbourhood notions shaping the suburbs were based on family-with-housewife ideals, the factual outcome is that the underground facilitates independent commuting of the household's grownups. Thus, in the MAMMUT project, we do not see the relations between the four aspects as unidirectional; neither causal, nor intentional. Instead, we study them in terms of interchange and mutual influence, as processes of change and of learning [15]. In the entire project, we should take this relations' analysis further than we did in the pilot studies. 


\section{PURPOSE}

2.1 Can situations of opportunity be analysed as formative moments?

In the previous section, we outlined the basic ideas of the MAMMUT project with examples from two of its pilot studies. In the next section, we present an in-depth discussion of the Daladala study. The description is structured by the main aspects of the draft theory of MAMMUT [9]. In Section 4, we introduce the concept of formative moments as presented by political scientists Bo Rothstein and Elinor Ostrom. Finally we discuss to what extent their concept could be used in our planned full-scale studies.

Thus, the main purpose of the paper is to confront political science theory with the empirical material in order to explore to what extent the conceptual framework of the MAMMUT programme could be developed in the process. From this purpose follows the paper's research questions:

- What characteristics have formative moments?

- Is the Daladala deregulation process a formative moment?

- To what extent can we identify and analyse a situation of opportunity and its field of options with the aid of the political science theories on formative moments?

\section{EMPIRICAL FINDINGS FROM THE PILOT STUDY}

\subsection{Daladala buses - deregulation and privatisation}

Dar es Salaam is a rapidly urbanizing city. Natural growth and migration contribute to a $3.1 \%$ annual growth rate. (Population in 1957: 128,742; in 2003: 3,000,000). In this section, we present basic results of the pilot study made within the MAMMUT programme, of the Daladala bus system. Main sources are interviews with two researchers of Tanzanian origin, and a literature review [16-20].

The zoning plan for Dar es Salaam, prepared by the Germans in 1891, guided urban development until the first master plan was developed in 1949. A new plan was made in 1968, but its implementation failed mainly due to lack of funds and political will. The latest master plan for Dar es Salaam was prepared in 1979. It is similar to the 1968 plan, but less 'radical' in terms of resettlement and redevelopment of slums and informal settlements. However, all master plans have been surpassed by a combination of rapid development of the city and delay in implementation.

By 2000, the administrative system of the city was restructured. The city council was divided into three municipalities: Ilala, Kinondoni and Temeke, together comprising 73 wards. In the same year, a Strategic Urban Development Plan was passed, based on the environmental planning and management process, which is part of the 'Sustainable Cities Programme' of the United Nations Centre for Human Settlements [21]. In the process, the city council held consultations with stakeholders and identified nine of the most pressing environmental management concerns for the city. One of these was urban transportation.

The public transport system of the colonial era worked considerably well until the independence of Tanzania in 1961, when Dar es Salaam's population began to grow rapidly. In part, this was due to the removal of restrictions for Africans to live in the city. In the 1970s, the formerly British-owned public transport company was nationalised and split into two semi-autonomous transport companies. One was Usafiri Dar es Salaam (UDA), responsible for public transport in the city, the other a company for inter-regional passenger transport. 
From the early 1970s until July 1997, fares for UDA services were fixed by a Price Commission and needed approval from the government. Fares did not cover the full cost, and since the government was unable to provide the required funds, UDA's performance was negatively affected. Rapid population growth and an obsolete, too small fleet of vehicles further enhanced the problems.

In the early 1970s, UDA was capable of supplying about $60 \%$ of the demand for public transport in the city. Since the government failed to strengthen UDA, the demand gap for public transport further increased over time and today UDA covers only $10 \%$ of the demand for public transport services. Therefore, private operators started to provide parallel services, and although the government banned private operators in 1975, they continued to operate illegally. Fares charged were up to five times higher than the public transport fares, to compensate for the risk involved.

In the 1980s, the Tanzanian government started the process of transition from planned to market oriented economy. This also affected the public transport sector. In 1983, the government began issuing licenses to private operators, allowing them to operate in parallel to the public system. UDA had the responsibility to regulate the operations of the private buses. In spite of this, the public transport in Dar es Salaam is quite disorganised today because a large number of individual bus operators work with little or no coordination. Privately owned mini-buses with a capacity ranging from 15 to 30 people constitute about $90 \%$ of the fleet used for public transport. This is the Daladala bus system.

In 2001, there were 40 bus routes in Dar es Salaam. Some areas, for example the city centre, are well served with bus routes. However, private operators are unwilling to serve areas that have poor roads. Buses operate between 5 am and $10 \mathrm{pm}$. Timetables do not exist and, although there are assigned bus stops, the bus driver will usually stop anywhere along the route, at the passengers' requests.

\subsection{Daladala buses - the urban structural, institutional, social and environmental aspects}

The existing road network of Dar es Salaam is satisfactory in the central area, but the roads that serve the suburban areas, where most people live, are poor. Even outside the centre, main roads are reasonably well maintained, but secondary roads are sometimes, for instance during the rainy season, not usable due to potholes. Most of the main roads built in the 1980s and 1990s have two lanes and cannot cope with today's number of vehicles. Thus, congestions are frequent. There is no proper access road to most informal settlements. In most parts of the city, the road network has no pavements, making it hard and dangerous to walk or cycle.

In housing areas outside the city centre, traditional types of one-storey houses dominate. This, coupled with the system of road network and car transport, creates the sprawl characteristic for the urban structure of large parts of Dar es Salaam. In turn, this structure results in long distances for commuting and other transport.

Main institutions on the national level are the Ministry of Communication and Transport and the Ministry of Home Affairs. In the city, the Dar es Salaam Regional Transport Licensing Authority is responsible for granting licenses to private service providers as well as for route allocation and control of operations.

The service providers of public transport are the city's UDA and the private Daladala bus owners/ drivers. Today, UDA owns between 20 and 30 vehicles operating in the city. About 6,000 Daladalas are licensed, but it is estimated that another 1,500 vehicles are operating without licenses. There are some private companies owning 10-15 mini-buses, but the majority of Daladala buses run on a 'one man-one bus' basis. The large amount of unlicensed buses indicates the licensing authority's low level of monitoring and compliance with its public mission. 
Main roads are laid out and maintained by the city authorities. In the informal settlements - a large part of suburban Dar es Salaam - little local government planning exists. Quite often, 'unwritten rules' define where a road should pass, and conflicts are usually resolved by local leaders.

Concerning the social aspect, the existing public transport system dominated by the Daladala buses is the only option for the majority of the poor living in Dar es Salaam. Besides buses, some people use bicycles, push carts or simply walk. Results of surveys conducted in the early 1990s indicate that public transport is used by $60 \%$ of the population, which uses motorised modes of transportation, and by $90 \%$ of the school-going children. Bicycles are used for goods transport and sometimes for trips related to farming activities. Cycling is considered dangerous, especially in the roads where Daladala buses transit. Walking is common for intra-settlement movements.

Children are often denied access to Daladala buses, especially during rush hours, because they are entitled to reduced fares (about $1 / 3$ of the adult fare). Bus drivers argue that this fare does not cover their costs, and they do not receive any compensation from the government. Depending on the route and time, people have to adjust to long waiting times at bus stops. Furthermore, Daladala mini-buses are usually overcrowded and poorly maintained.

Most of the traffic accidents in the city involve Daladala buses. This is in part due to reckless driving, but also because of the lack of proper walking or cycling paths.

With a wide definition, environmental impacts related to Dar es Salaam's public transport system come from the construction, operation, use and demolition of vehicles and roads. However, in the MAMMUT pilot studies, we have a narrower definition. Since the fossil fuels used in operation create a major impact, energy use is the chosen environmental 'indicator'. In this pilot study, we have only illustrated how impacts could be quantitatively assessed.

The commuting distances for the Dar es Salaam region in person-kilometres per year for private cars, buses and Daladalas can be obtained from statistics. Statistical averages for energy use per passenger-kilometre and vehicle type are available, but first the main fuels used must be identified. Based on this, the total energy use per vehicle type and passenger-kilometre can be recalculated into environmental impact categories (for example carbon dioxide emissions) using LCA methodology.

Two opposing tendencies will influence the outcome of calculations, as compared to a city in a high-income country, for example Stockholm. On the one hand, crowded Daladala buses may result in smaller environmental impacts per passenger-kilometre than the Swedish private car, the latter on an average transporting one to two persons. On the other hand, fuels of inferior quality and bad vehicle maintenance will certainly cause larger environmental impacts per vehicle-kilometre. If the perspective is expanded to comprise all modes of transport of persons, Stockholm's large share of commuting by underground and train $(60-70 \%)$ must be considered.

\section{3 'What if' - the counterfactual commuter train alternative}

In a historical situation of opportunity, there is a factual outcome; in the Daladala case it was public transport supplied by small enterprises in a market economy and with almost no societal control. Were alternatives formulated? We have not been able to investigate this in the pilot study. We have, however, outlined a counterfactual scenario. The main purpose of doing this was to illustrate the MAMMUT concept of field of options. Thus, the scenario is an attempt to create an alternative that is contrasting to all four aspects, especially the environmental aspect. (We have, however, not been able to assess the realism of the alternative.)

The main assumption of the counterfactual scenario is that the local government succeeded in maintaining control over public transport, and developed a system for commuting based on two existing railways. One is part of the national railway connecting Dar es Salaam towards the west and 
lake Victoria, the other an industrial railway going towards the northwest. The latter is assumed to have been extended westwards from the suburb of Ubungo for about $15 \mathrm{~km}$. Along these railway lines, we assume that commuting stations were built at $\approx 3 \mathrm{~km}$ intervals. Furthermore, we assume that the road network was developed with pavements and cycling paths along the main roads. This, together with improved maintenance, should give better accessibility even during the rainy season.

As a result of these measures, the urban structure aspect would have been different. Adjacent to the commuter train stations, local markets, shopping centres and low income housing areas developed. Furthermore, we assume that this lead to a more dense urban structure, comprising 3-5 storey houses. (This assumption might be contrary to theories on urban economic development as well as underestimate the cultural inertia [22-24]).

The main institutional set-up remains the same as in the Daladala system, but we assume that institutions have grown stronger in terms of non-corruption and law enforcement. In other words, they have succeeded in improving their monitoring and compliance systems. Furthermore, the urban planning authority was strengthened in the same way. Thus, UDA is responsible for both commuter train transport and for regulating the bus transport system: Daladala mini-buses provide transport along routes predefined by UDA, and UDA is able to enforce the regulations concerning these.

Timetables for public transport reduce waiting times in citizens' every day life, influencing the social aspect. The denser urban structure allows for shorter commuting distances. Better roads and better-organised traffic help to reduce traffic hazards and facilitate safe travel of school children. Living in multi-storey buildings will call for other, less traditional ways of life than the one-storey buildings that dominate today's 'real' suburbs.

The basic approach for defining and analysing the environmental outcome of the counterfactual scenario remains the same as that for the factual outcome. The impacts of energy use for operating the public transport system are the environmental indicator. The main modes of transport are commuting by trains, private cars and mini-buses, all assumed to be fossil fuel driven. Due to better traffic separation, a higher share of walking and bicycling is assumed. On the one hand, commuting distances will be shorter; on the other hand, higher reliability will increase mobility. However, on the whole, environmental impacts both in terms of vehicle-kilometres and passenger-kilometres are assumed to be lower than the present factual situation.

\section{THEORY AND DISCUSSION}

\subsection{Rothstein - tools for identifying formative moments}

In MAMMUT's conceptual framework a situation of opportunity is a moment in time when the actors of a given policy area have access to a set of profoundly differing alternatives. Together, these alternatives define the situation's field of options. Political scientist Bo Rothstein understands these situations as formative moments [1]. Such moments of institutional and political instability are characterised by changing economic and social circumstances that make existing political institutions unfit to deal with an occurring situation or a crisis [25].

Furthermore, Rothstein's hypothesis is that during these formative moments in social and political history, a possibility opens up for strategically skilled actors to reshape the political institutions, entering into a positive (or negative) development spiral. Empirically it is a matter of finding these moments. Theoretically it is a question of to what extent decisions in these Moments were perceived as 'rational choices' by the involved actors [1]. However, the issue of rationality is, far from uncontroversial, since it depends on the type of rationality that is assumed. Is the actors' freedom of action equivalent to the full rationality of 'economic man' or is it relative, dependent on the situation and 
thus bounded [26]? This discussion is closely related to the one of the alternatives available, or in MAMMUT terms, how wide the field of options is.

The structure of Rothstein's proposed scenario looks like this [1]:

1. Initially, an economic or political crisis occurs;

2. there are demands on political action to remedy the consequences of the crisis;

3. the eagerness and ability of the involved actors to engage in strategic manoeuvring is put to the test;

4. new political institutions is one possible outcome of the crisis;

5. new rules and procedures for economic actors is another possible outcome, and finally

6. the outcome might be the creation of new political power constellations.

Let us now apply the above to the empirical findings of the Daladala bus system. It seems clear that what we identified as a situation of opportunity is a formative moment according to Rothstein's definition. It was initiated by a political crisis at the national level - the turnover from the planned economy towards market orientation. This called for action on the city authorities' level. It seems equally clear that the local government did not succeed in handling the situation; new actors outside the political arena took over. Today, only some tens of a total of 6,000-7,000 buses are run by the city's main actor, UDA. Also in its new role as controller of private enterprises, UDA has failed to a large extent; the rules for the new actors are there but have not been implemented. In other words, UDA is unable to operate as a monitoring and enforcing control institution, and no new political powers have been established. Thus we arrived at a situation where 'public' transport is a matter of small-scale market economy with very little of public control.

Applying Rothstein's scheme to the pilot study's counterfactual scenario seems equally possible. (We do not know, however, if Rothstein would approve of this approach; discussions starting with counterfactual 'what if' assumptions remain controversial). That scenario too, is a formative moment. In this case, we assume that the call for action resulted in the strengthening of an existing actor, the UDA. The main part of the outcome is a new means of transport, commuting by train. Furthermore, we assume that UDA in its role as controller of the privatised bus system as well as operator of the railway system became more successful.

Our purpose as a cross-disciplinary group of researchers is wider than that of Rothstein's as a political scientist. Our 'object of study' is synergies between the processes of urbanisation and sustainable development, our main strategy to identify and analyse situations of opportunity. Thus we looked for outcomes outside the institutional field: Changes in the ways of life of households and citizens, new urban structures and housing patterns and last but not least the environmental impacts. In the pilot study, we tested only the feasibility for doing so. We can, however, observe that with this purpose of the research group, we go beyond what can be provided by the political scientist's tool of analysis. Within the institutional aspect of MAMMUT's conceptual framework, Rothstein's description of formative moments should help analysis. We can furthermore assume that in general it should help identifying MAMMUT's situations of opportunity.

\subsection{Ostrom - tools for analysing situations of opportunity}

Elinor Ostrom states that the obvious starting point for analysing, predicting and explaining behaviour within institutions is to identify the unit of investigation [2,3]. This unit she calls the action arena. To us, it is closely related to a wide definition of a situation of opportunity. The arena includes a concept called action situation and the actors involved in it. Ostrom's action 
situation is the formative moment of our situation, seen without its prehistory or resulting outcome. According to Ostrom, the action arena is characterised by seven variables. These, we prefer to call categories [3]:

1. Participants; individual and collective actors;

2. positions; are the actors influential or marginal;

3. outcomes;

4. action-outcome linkages;

5. the control that participants exercise;

6. information; and

7. the costs and benefits assigned to the outcomes.

Most of these seven categories are identified in our Daladala pilot study. The participants and their positions were made clear; the outcome was described in institutional, social, environmental and urban structure terms. We could see that the participants gradually lost control, and so far neither they nor the new ones have fully regained it. Thus, we identified the main outcomes and their linkages to the action situation. However, we did not analyse the outcome in terms of cost and benefits in the monetary sense, but rather in terms of reliability and service for the users of Dar es Salaam's public transport system. In addition, we proposed a way of assessing the outcome in terms of environmental impacts. Therefore, we conclude that the situation that was analysed through the use of MAMMUT's conceptual framework is an action arena and action situation in Ostrom's theory.

Unlike Rothstein, Ostrom did not explicitly call for the identification of alternative actions. One reason for this could be that Ostrom is extremely empirically oriented and focuses on the ongoing [2, 3, 27]. This differs from the MAMMUT idea of defining a field of options through creating counterfactual scenarios. On the other hand, Ostrom's theory is applicable to almost every conceivable situation [28].

In our analysing the counterfactual scenario with Ostrom's theory, we arrive at the same conclusion as with Rothstein; the scenario can be understood as an action arena. Describing it in terms of Ostrom's categories helps us to analyse the institutional aspect of a MAMMUT situation of opportunity, but our cross-disciplinary approach calls for a wide definition of outcomes.

\subsection{Analysing the actors, considering cultural differences}

Ostrom proposes that the analysis of action arenas should be taken one step further. She indicates that the participants, individual as well as collective, bring in four clusters of variables into the action arena [3]:

1. the resources that an actor brings to a situation;

2. the valuation actors assign to states of the world and to actions;

3. the way actors acquire, process, retain, and use knowledge and information; and

4. the processes actors use for the selection of particular courses of action.

This second step of analysis goes beyond what was done in the pilot study. None of these aspects could be identified from our interviews with experts, through analysis of books or other secondary sources. To us, it seems difficult to analyse historical situations this deeply, at least when the participants themselves are no longer accessible for questioning (as in the Stockholm pilot study, mentioned in the introduction). Its main use seems to be in ongoing or recently terminated 
processes. Furthermore, we are hesitant as to whether this in-depth analysis of the actors' motives and resources is beneficial for MAMMUT's purpose.

It is common among social scientists to stop the theoretical development at this level and take the further use of it as uncontroversial. Then, the 'normal' analysis proceeds towards predictions of likely behaviour of actors within a given structure [3]. In a narrow sense of the word, we are not interested in prediction from historical studies; we do not ask what will happen during the early 2000s as a result of the development of the public transport system up till now. However, in a full-scale MAMMUT project we intend to model future scenarios, 50 years from now. From them, we will try to connect the scenario with the present using the technique of backcasting [29-31]. We assume that in backcasting we will be able to develop future situations of opportunity. Learning how to do this is the main purpose of the historical studies.

Finally, Ostrom stresses the importance of identifying the differences between formal and informal rules when analysing action arenas. When investigating institutional change in a developing and culturally differing society, the field researcher from a high-income nation will encounter situations that are bound to confuse. Ostrom lists six such challenges and difficulties [3]:

1. institution as a concept refers to a variety of different entities, including both organisations and the rules and decision-making procedures used to manage these organisations;

2. institutions are often identified with representative buildings they occupy, but the institutions themselves are more illusive;

3. developing a coherent perspective when investigating different types of institutional arrangements (markets, hierarchies, business companies, families, voluntary associations, national, regional and local governments and various international regimes) calls for inputs and ideas from a multitude of disciplines;

4. using the multitude of languages and paradigms introduced from this variety of disciplines, a coherent conceptual framework is needed to make it possible to put forward different theories and models applicable to different problem areas and settings;

5. institutional studies need to encompass multiple levels of analysis, because decisions about rules are made on different levels than the one they applied on; and

6. on any specific level of analysis, rules, attributes of the world, individuals and communities combine in a configural rather than an additive manner.

Unlike the previous parts of Ostrom's theory, this third part takes the form of statements, rather than a checklist of categories to be analysed. Once again, most are relevant for the MAMMUT project. In the pilot study, we identified the differences between the institutions as systems of rules and as organisations. We also noted the difference between formal power, institutions' symbols (buildings etc.), and their real achievements. (This, of course, applies mainly to the factual situation; we can hardly investigate the counterfactual scenario in these terms.)

Ostrom's comments on multi-disciplinarity [3] are highly relevant to MAMMUT: our concept of institutions is by needs wide; within the group of actors we might also include individuals or loosely formalised co-operation in informal settlements. Analysis of this is simplified by having different disciplinary backgrounds. Furthermore, one of our main objectives is the development of a cross-disciplinary conceptual framework of the kind, as mentioned above in the fourth point.

Ostrom's final point reminds us of a basic assumption in MAMMUT: full understanding of the situations of opportunity cannot be achieved through analysis of each aspect separately; rather it lies in studying the relationships between the environmental, social, institutional and urban structure aspects, and in seeing these relations as mutual interdependencies rather than as unidirectional. 


\section{CONCLUSIONS}

This paper started with the introduction of the MAMMUT project's main concept, situations of opportunity, and its main characteristic element, the field of options. We then presented empirical findings of the development of the Daladala bus system as a historical situation of opportunity (albeit a lost one). This presentation was structured by the four main aspects of institutional, social, environmental and urban structure. To define the situation's field of options, we constructed a counterfactual scenario based on commuting by train. We assumed that this scenario would lead to a more dense urban form, and would also differ in the other aspects. Section 3 of the paper introduced theory from political science on formative moments that was tested against the empirical findings.

A main conclusion from Section 3 is that MAMMUT's situations of opportunity are closely related to the concept of formative moments. However, we do not see them as identical: situations of opportunity is a wider concept in scope as well as in time. It includes a prehistory as well as a set of factual and counterfactual outcomes; also, the prehistory and the outcomes should be described in cross-disciplinary terms. On the other hand, formative moments are a specific political scientist's understanding of actors seizing an opportunity in a specified situation. All the same, the identification of historical situations of opportunity can benefit from Rothstein's hypotheses on the properties of formative moments.

Ostrom's categories characterising an action arena are also useful when analysing a situation of opportunity, once it is identified. They will, however, assist analysis mainly of the institutional aspect of the concept of cross-disciplinary situations. Her comments on the difficulties of applying theories from high-income countries to the conditions in developing countries are highly relevant. A main strength of her approach is the extreme empirical orientation.

A further, more comprehensive reflection is that the situations of opportunity as well as the formative moments are occasional interruptions in the normal, everyday process of 'muddling through'. Political economist Charles Lindblom used this concept to describe an incremental process where decisions are consequences of a historical record of previous decisions [32, 33]. Furthermore, he stated that this process of gradual improvement and change is much more common than the full rationality often assumed in theories from political science, business economy or environmental management (e.g. compare the international standards for environmental management, the ISO 14000 series). Thus, we conclude, in the normative perspective of sustainable development, situations of opportunity and formative moments are the exceptions sorely needed.

In the future development of MAMMUT theory, the social, environmental and urban form aspects should be developed along the same lines as the institutional one; they should be related to theory from sociology or anthropology, natural science and planning. Members of the cross-disciplinary group of researchers should compile background material from their respective disciplines, the group analysing the combination of theory with empirical material.

Another important observation from the discussion in Section 3 concerns the events leading up to a formative moment. Neither Rothstein nor Ostrom include analysis of the prehistory of a formative moment in their theories. In other words, they do not explicitly relate to Lindblom's theory of 'muddling through'; one explanation could be that they have higher confidence in rationality than Lindblom had. Here, we take the middle way: from our pilot studies of Stockholm and Dar es Salaam we concluded that the stakeholders of a situation might be restricted by decisions taken in previous years or by routines in the decision-making process. Thus, even though an outside observer or a researcher analysing the situation afterwards could identify a wide field of options, the stakeholders would have disagreed, if asked at the formative moment. They might not even be aware of their being in a situation of opportunity. From this we conclude, that one main aims of the MAMMUT project should be to develop 'early warning systems' - tools that help stakeholders of future 
situations of opportunity to identify that they are approaching such a situation, and help them to identify as wide a field of options as possible.

The next step in the development of the MAMMUT project is taking the experience gained so far into the studies of the future. This will be a large, qualitative leap; calling for another two research methodologies, scenario building and backcasting. The main uncertainty here, we assume to be the backcasting part: How can we identify and develop future situations of opportunity through backcasting from scenarios located in the 2050s? In a recently started project 'Situations of opportunity in the growth and change of three Stockholm City districts - everyday life, built environment and transport explored as energy usage systems' a first such attempt is made by some of the researchers involved in the Daladala and Stockholm pilot studies [34]. Hopefully, this research challenge will benefit from pilot studies like the one reported in this paper.

\section{REFERENCES}

[1] Rothstein, B., Den korporativa staten: Intresseorganisationer och statsförvaltning i svensk politik; Norstedts juridik, Stockholm, 1992.

[2] Ostrom, E., (ed.). Aid, Incentives, and Sustainability: An Institutional Analysis of Development Cooperation, Main report, Sida Studies in Evaluation 02/01, 1998.

[3] Ostrom, E., Institutional rational choice: an assessment of the institutional analysis and development framework. Theories of the Policy Process, ed. A. Sabatier, pp. 35-72, 1999.

[4] Svane, Ö. MAMMUT - Managing the Metabolism of Urbanisation, Research programme, Stencil, KTH Built Environment Analysis, Stockholm, 2003.

[5] European Commission, European sustainable cities: Expert Group on the Urban Environment, European Commission, Directorate General XI, Environment, Nuclear Safety and Civil Protection, Office for Official Publications of the European Communities, Luxembourg, 1996.

[6] Jenks, M., Burton, E. \& Williams, K. (ed.), The compact city: a sustainable urban form? E \& FN Spon, London, 1996.

[7] Kingdon, J.W., Agendas, Alternatives and the Public Policies, Harper Collins: New York, 1995.

[8] Rothstein, B., Political institutions: an overview. A New Handbook of Political Science, eds R.E. Goodin \& H.-D. Klingemann, Oxford University Press: Oxford, 1996.

[9] Svane, Ö. \& Weingaertner, C., MAMMUT - managing the metabolism of urbanization: testing theory through a pilot study of the Stockholm underground. Sustainable Development, 14(5), pp. 312-326, 2006.

[10] Gullberg, A. \& Kaijser, A., City building regimes in post-war Stockholm, KTH: Stockholm, 1998.

[11] Baccini, P. \& Baader, H.-P., Regionaler Stoffhaushalt Erfassung, ewertung und Steuerung, Spektrum Akademischer Verlag: Heidelberg, 1996.

[12] Bringezu, S. \& Moriguchi, Y., Material flow analysis. A Handbook of Industrial Ecology, eds R.U. Ayres \& L.W. Ayres, Edward Elgar Publishing: UK, 2002.

[13] United Nations, Rio declaration on environment and development, United Nations Conference on Environment and Development, Rio de Janeiro, Brazil, 3-14 June 1992, www.unep.org

[14] Valentin, A. \& Spangenberg, J.H., Indicators for Sustainable Communities, www.wuppertalinstitut.de, 1999.

[15] Weingaertner, C., Analysing Synergies between Urbanization and Sustainable DevelopmentDeveloping a Draft Theory through Historical Pilot Studies, KTH: Stockholm, http://www.diva-portal.org/kth/theses/abstract.xsql?dbid=447, 2005. 
[16] Lugalla, J., Crisis, Urbanization and Urban Poverty in Tanzania: A Study of Urban Poverty \& Survival Politics, University Press of America, 1994.

[17] Lupala, J., Urban Types in Rapidly Urbanising Cities Analysis of Formal and Informal Settlements in Dar es Salaam, Tanzania, KTH Built Environment Analysis: Stockholm, 2002.

[18] Nguluma, H., Housing Themselves Transformations, Modernisation and Spatial Qualities in Informal Settlements in Dar es Salaam, Tanzania, KTH: Stockholm, 2003, http://www.diva-portal. org/kth/theses/abstract.xsql?dbid=3494

[19] Sohail, M., (ed.). Partnership to Improve Access and Quality of Public Transport - A Case Report: Dar es Salaam, Tanzania, WEDC, Loughborough University: UK, 2003.

[20] Sutton, J.G., (ed.). A sketch of hundred years. Tanzanian Notes and Records, No. 71, 1970.

[21] UN-HABITAT, The Sustainable Cities Programme in Tanzania 1993-2003, United Nations Environment Programme: Nairobi, Kenya, 2004.

[22] Andersson, R., Stadsbyggnadsekonomi, Studentlitteratur, Lund, 1991.

[23] Blomqvist, H. \& Lundahl, M., Ekonomisk utveckling: En introduktion till u-ländernas ekonomiska problem, SNS Förlag: Stockholm, 1992.

[24] Inglehart, R., Culture Shift in Advanced Industrial Societies, Princeton University Press: New Jersey, 1990.

[25] Rothstein, B., Aktör-Struktur ansatsen. Ett metodiskt dilemma. Statsvetenskaplig Tidskrift, 91, p. 37, 1988.

[26] Odell, J.S., Negotiating the World Economy, Cornell University Press: Ithaca and London, 2000.

[27] Ostrom, E., Governing the Commons: The Evolution of Institutions for Collective Action, Cambridge University Press: New York, 1990.

[28] Sabatier, P.A., (ed.). Theories of the Policy Process, Westview Press: Boulder and Oxford, 1999.

[29] Dreborg, K.H., Essence of backcasting. FUTURES, 28(9), pp. 813-828, 1996.

[30] Dreborg, K.H., Scenarios and Structural Uncertainty Explorations in the Field of Transport, Ph.D. thesis, KTH: Stockholm, 2004, http://www.diva-portal.org/kth/theses/ abstract.xsql?dbid=3697

[31] List, D., Multiple pasts, converging presents, and alternative futures. Futures, Elsevier, 36, pp. 23-43, 2004.

[32] Lindblom, C., The science of muddling through. Public Administration Review, 19, pp. 79-88, 1959.

[33] Lindblom, C., Politics and Markets, Basic Books: New York, 1977.

[34] www.infra.kth.se/sitcit 